\title{
DE LA IMITACIÓN A LA PARTICIPACIÓN. EL PLATONISMO DE LOS AGUSTINOS TOMÁS DE VILLANUEVA Y FRAY LUIS DE LEÓN
}

\author{
FROM IMITATION TO PARTICIPATION. THE PLATONISM ON THE
} AUGUSTINIAN THOMAS DE VILLANUEVA AND FRAY LUIS DE LEÓN

CHRISTOPH STROSETZKI

Westfälische Wilhelms Universität Münster-IEHM

\section{RESUMEN}

Este artículo estudia en qué medida los monjes agustinos Tomás de Villanueva (1486-1555) y Fray Luis de León (1527-1591) adoptaron y transformaron elementos de la doctrina platónica. En este artículo se reflexionará sobre la importancia de la methexis $(\mu \varepsilon \varepsilon \varepsilon \xi 1 \varsigma)$ y la parousía ( $\pi \alpha \rho o v \sigma i ́ \alpha)$ para la idea y la idea suprema, sobre las implicaciones de la idea suprema para la moral, sobre el desprecio por lo material como consecuencia de la sobrevaloración de la idea y sobre las metáforas platónicas.

Palabras clave: Tomás de Villanueva, Fray Luis de León, platonismo, imitación, participación.

\section{ABSTRACT}

This article studies to what extent the Augustinian monks Tomás de Villanueva (1486-1555) and Fray Luis de León (1527-1591) adopted and transformed elements of the Platonic doctrine. This article will reflect on the importance of methexis ( $\mu \varepsilon \dot{\theta} \theta \xi \xi_{1}$ ) 
and parousía ( $\pi \alpha \rho o v \sigma i ́ \alpha)$ for the idea and the supreme idea, on the implications of the supreme idea for morality, on the contempt for the material as a consequence of overvaluation on the idea and on Platonic metaphors.

Keywords: Tomás de Villanueva, Fray Luis de León, Platonism, imitation, participation.

A San Agustín se le atribuye la vinculación del cristianismo con la filosofía de Platón. El interrogante que surge entonces es en qué medida los monjes agustinos Tomás de Villanueva (1486-1555) y Fray Luis de León (1527-1591) adoptaron y transformaron elementos de la doctrina platónica. En este artículo se reflexionará sobre la importancia de la methexis $(\mu \varepsilon \dot{\varepsilon} \theta \varepsilon \xi 1 \zeta)$ y la parousía ( $\pi \alpha \rho o v \sigma i ́ \alpha)$ para la idea y la idea suprema, sobre las implicaciones de la idea suprema para la moral, sobre el desprecio por lo material como consecuencia de la sobrevaloración de la idea y sobre las metáforas platónicas.

En primer lugar, recordemos brevemente la teoría de las ideas de Platón. Estas son independientes y trascendentes, es decir, se distinguen del mundo perceptible. La alegoría de la caverna en la Politeia de Platón (VI 506 y 3ss) describe el camino del hombre a través del mundo de los fenómenos y de las ideas hacia Dios a través de cuatro niveles de conocimiento: palabras, percepciones, conceptos e ideas. Al comienzo parece como si estuviera encadenado mirando a una pared. Que los objetos reflejados allí son solo sombras de objetos y figuras que se mueven detrás de él y que son iluminados por el fuego solo queda claro para él cuando, liberado de sus grilletes, se da la vuelta y, cegado por el fuego, puede ver las cosas originales cuyas sombras tenía antes delante de él. Mientras que en la primera fase solo se ocupaba de las palabras, ahora en la segunda percibe los fenómenos empíricos. En la tercera fase abandona la cueva con su penumbra y escala al mundo superior con la claridad del día. Ya no se encuentra en el espacio visible sino en el espacio concebible y ve en los reflejos de las estrellas y en las aguas terrenales los conceptos como imágenes de las ideas. Finalmente, en la cuarta y última fase, aparta la mirada de la tierra y la dirige hacia el cielo, donde ve las ideas como estrellas y al sol que ilumina todo como la idea suprema. Le queda claro que ella es la creadora de todo lo que vio en su camino precedente. Así como allí el sol hace posible ver y ser visto a través de su luz, así la idea suprema, la idea del bien, es la razón para el reconocimiento de las ideas. Platón también describe la idea del bien como una deidad, un demiurgo que da forma a todo para el bien. En el diálogo Parménides (137 c 4- 
142 a 8), la idea suprema no es la pluralidad, sino la unidad que reúne en sí toda la pluralidad de una manera suprema.

La idea platónica es un arquetipo en el que participan todas las diferentes cosas individuales que son parte del concepto o que pertenecen a la misma clase. La relación del objeto aislado con la idea correspondiente puede describirse como participación o incluso imitación, en la cual la idea es el arquetipo y la cosa individual la imagen. Platón lo expresa a través del concepto de imitación (mímesis). Cuando el mundo empírico imita las ideas, estas parecen ser más originales y valiosas. En Phaidon (99 b 3s) la idea también se describe como la verdadera razón y causa de la cosa individual. Aquí hay dos direcciones para su consideración: la methexis que se refiere a la participación de la cosa individual en la idea, mientras que la parousía se refiere a la presencia de la idea en la cosa individual. Como es sabido, Platón había descrito en su diálogo Menon (97) cómo el alma tenía conocimiento de las ideas antes de nacer, pero lo pierde en el momento del nacimiento por la conexión con el cuerpo y sólo puede recuperarlo a través del recuerdo. Mientras que las percepciones sensoriales dan lugar a opiniones, las ideas aportan un conocimiento fundado.

No fue San Agustín el primero en vincular las ideas de Platón al cristianismo, pues ya había influido en las formulaciones del Nuevo Testamento ${ }^{1}$.Según el evangelio de Juan el Logos está en el principio, el cual como Dios crea al mundo, en el que las ideas se vuelven reales, y Cristo habitaba entre los hombres como la luz en la oscuridad de la materia, lo que nos lleva a pensar en Platón. Ya el filósofo judío Filón de Alejandría (15/10 a.C. - 40 d.C.) relaciona el relato de la creación del Antiguo Testamento con el Timaios de Platón, separa el mundo ideal extrasensorial del visible sensorial y ve la creación del mundo como la obra de un maestro constructor, un demiurgo, que, según sus ideas, moldea el mundo material y crea el mundo sensorial.

Para el neoplatónico Plotino, el punto de partida para la existencia de la pluralidad es algo simple, ya que una progresión mental de lo más complejo a lo más simple conduce a lo más simple. Plotino llama a esta simplicidad "el Uno" (en griego $\tau$ ò Ẽv). El Nous como un determinado Algo emana del indiferenciado Uno sin que la fuente misma se vea afectada y cambie en el proceso. Plotino ilustra esta emanación con la imagen del sol, del que emanan incesantemente rayos de luz, sin que se vea afectado y cambiado. Dado que, según Plotino, el cuerpo solo está conectado externa y temporalmente con el alma, la búsqueda del placer físico debe ser evitada. Los bienes externos son irrelevantes para la

1 Cf. para lo que sigue:(Gronau 1929, 27-47). 
felicidad, ya que no pueden aumentarla. Lo malo es solo la ausencia de lo bueno. Por lo tanto, el mal no es un poder en sí mismo, sino algo vacío, con necesidades y sin poder, que se supera centrando constantemente la atención en el bien, surgiendo a través de la cosmología consecuencias para la moral.

También para San Agustín la idea platónica suprema se equipara con Dios, quien creó todo según las ideas contenidas en él mismo. Para él, la cognición humana es la participación en el conocimiento divino de las ideas. Al defender San Agustín, así como Plotino, el monismo del bien, se vuelve contra los maniqueos, que ven el bien y el mal equivalentes. Si San Agustín distingue la civitas Dei de la terrena civitas, la civitas debe entenderse como una comunidad y no como un territorio, como el Lazio, que podría llamarse urbs. El modelo para esto es el estado romano, cuyos derechos civiles tenían un alcance mundial. Uno seguía siendo un ciudadano de Roma, sin importar a dónde fuera. Con la frase "civis romanus sum", el romano se da a conocer y conecta con ella el derecho mundial a no ser torturado u obligado a realizar trabajos forzados y, en el caso de una acusación, a tener el derecho al debido proceso legal. Las civitas Dei y las civitas terrena de San Agustín tienen que ser pensadas de manera similar. Las ve como dos comunidades que coexisten desde el comienzo y hasta el final de la historia del mundo, en las cuales la primera se caracteriza por el amor a Dios que llega hasta el desprecio de uno mismo y la segunda por el amor a uno mismo que llega hasta el desprecio de Dios (Redkova 2018, 155-56). Por su comportamiento el individuo puede así pertenecer a una u otra comunidad. La primera está representada metafóricamente por la Jerusalén bíblica y la segunda por Babel, marcada por la confusión. El mundo material, en el sentido agustiniano, ofrece tentaciones, especialmente en las ciudades, y brinda oportunidades para el orgullo y la lucha por el poder terrenal, por lo cual los patriarcas no habrían fundado ciudades sino que habrían vivido como pastores. Su peregrinatio pro Christo pudo entonces ser modificada por los monjes, como el cisterciense Bernardo de Clairvaux, en peregrinatio in stabilitate y fue trasmitida a la comunidad monástica, que fue percibida como una ciudad celestial, civitas Dei peregrinans, porque ofrecía un espacio libre del mundo con sus distracciones materiales, enteramente al servicio de la espiritualidad (Redkova 2018, 158).

Esta mirada a la teoría platónica de las ideas y a sus primeros receptores hasta San Agustín ha mostrado algunas constantes. Por la orientación hacia la idea suprema del bien, lo espiritual se vuelve más importante que lo material, lo que lleva al rechazo de lo material y a la preferencia por lo espiritual, llamándose también a lo primero el mundo exterior y a lo segundo el mundo interior. Así como los objetos individuales participan de la idea y esta brilla a través de ellos, así el hombre debe orientarse de acuerdo con la idea suprema del bien. Si la 
trasmite a través de sus acciones y pensamientos, es parte de ella a través de la parousía y la methexis. El seguimiento de Cristo expresado platónicamente aparece como una imitación de la idea suprema que se ha convertido en hombre. En el contexto platónico, la idea suprema se distingue fácilmente de la oscuridad de la materia a través de metáforas del sol y de la luz. Se plantea entonces la interrogante de cómo los monjes agustinos Tomás de Villanueva y Fray Luis de León adoptan o bien modifican las ideas platónicas.

Antes de introducirnos en las enseñanzas de Tomás de Villanueva, veamos primero el cuadro que Francisco de Quevedo pinta de él en su resumida biografía. Siguiendo el patrón tradicional de la retórica de alabanza, comienza con un evento milagroso: en su lugar de nacimiento, la peste había cesado con motivo de su nacimiento. A los siete años de edad, Tomás volvió dos veces a su casa sin ropa, ya que se la había entregado a un hombre pobre por misericordia, lo que hizo feliz al hombre y a los padres del futuro santo (Quevedo 1859, 59). Y más tarde mantuvo esta actitud, por lo que también se le llamó "padre de los pobres" (Quevedo 1859, 60). Evitaba las apariencias. Prefirió el silencio a una conversación superflua. Su vida transcurrió principalmente en cinco lugares: en la iglesia, en el altar y en el coro para rezar, en su celda para meditar, en la biblioteca para leer y en la enfermería, el lugar de su caridad. Todos los demás lugares le parecían "cautiverio y prisión” (Quevedo 1859, 60). Cuando fue predicador de Carlos V y este quiso hacerle una visita, lo rechazó según Quevedo, señalando que tenía que preparar su sermón. Mientras que el séquito del emperador interpretó esto como una gran descortesía, este apreció esta reacción, que mostraba de manera ejemplar que el hermano Tomás no se dejaba impresionar por las vanidades externas y el poder mundano. En vista de los numerosos cargos y responsabilidades que Tomás desempeñó como profesor universitario, arzobispo y provincial de la Orden, parece necesario subrayar que fue ante todo "amante [...] de la observancia y retiro de su religión y su celda" (Quevedo 1859, 62).

Una actitud acorde también es evidente en los propios escritos de Tomás de Villanueva. En su Modo breve de servir a nuestro señor en diez reglas precede un prólogo en el que llama a la ruptura con el mundo material, que opone como "obscuridad del sueño de esta vida" a la "verdadera luz del día" (Villanueva 1952, 508), adoptando así la metáfora de la luz de la idea platónica suprema de la Parábola del Sol. En el interés del mundo ideal aconseja la soledad, la clausura, el silencio y la oración. Su consejo es "huir conversaciones de mundanos, que ahogan el espíritu y buen deseo del ánima devota, huir visitaciones de seglares y procurar alguna conversación de alguna persona verdaderamente espiritual" (Villanueva 1952, 508). Deben ser evitados y aún más despreciados todos los 
placeres y deleites mundanos y vanos, riquezas, honras y favores. Para ello se buscan deleites interiores del espíritu y del entendimiento. Es importante un lugar para orar. Allí es posible "mirar desde allí, como desde alto, las cosas de esta vida, los trabajos vanos y ansias superfluas de los hombres y los errores de los mundanos. [...] Esta es verdadera vida, porque lo demás que se emplee en negocios y curiosidades del mundo, todo lo ha perdido. Mucho le va al cristiano en se emplear bien en esto y vivir consigo y no andar desterrado fuera de sí y extrañado en ocupaciones vanas y sin fruto, que parecen y son dañosas para el ánima" (Villanueva 1952, 509). Sobre lo que le ha pasado a otros, se debe evitar escuchar, leer o contar cualquier cosa, que pueda despertar la curiosidad (Calatayud Gil 1956, 29). "Ocuparse todo en sí y vivir siempre consigo" (Villanueva $1952,510)$. Este es el lema, pero no un fin en sí mismo, porque sirve para concentrarse en la vida de Jesús a través de la lectura, la meditación y la oración, "porque la lección santa muestra el camino del cielo, la meditación lo anda, la oración lo consigue" (Villanueva 1952, 512). A través del trabajo espiritual y la imitación de Cristo se llega a participar de lo divino, por lo cual el camino desde la cueva platónica hacia la idea suprema se convierte aquí en el camino del cielo.

En su escrito De la lección, meditación, oración, contemplación (Villanueva 1952, 514-26) muestra el significado de las distintas etapas. La lectura de libros es similar a las conversaciones y las visitas, "porque de las malas palabras se nos causan malos pensamientos; de pensamientos, deseos; de malos deseos, obras y ruines costumbres; y al contrario, de las buenas palabras, etc., porque 'la buena lección'es manjar del alma, el cual se come y muele con la meditación, y con la oración" (Villanueva 1952, 514-15). ¿Qué deseo despierta la buena lectura? Nos recuerda la idea suprema de Platón, la de lo bueno y lo bello al mismo tiempo, cuando Tomás habla del "deseo que tiene de alcanzar esta hermosísima vista de Dios, en quien tanto y todo su bien consiste" (Villanueva 1952, 515). Como Aristóteles, piensa excepcionalmente, cuando no ve lo bueno o lo bello de Dios como accidentes "el hombre y el ángel por accidente son buenos, mas Dios esencialmente y sustancialmente es bueno, no por alguna cosa a Él unida, al cual su ser es ser bueno" (Villanueva 1952, 609). Cuando el estudio de una cosa cierta, que, como la idea suprema de Platón, existe sólo una vez, es la meta, entonces la diversidad y la preocupación por las cosas diferentes son una desviación perjudicial, que Tomás enfatiza, citando el consejo de Séneca a Lucilio. Las abejas también eligen siempre solo lo mejor para su miel. En vista de la brevedad de la vida, es aconsejable "de no perder un solo punto de tiempo sin nos ocupar en algún buen pensamiento" (Villanueva 1952, 517). En este contexto, la virtud de la caridad cultivada por Tomás, que Argimiro Turrado ve como la virtud central en la Orden Agustina (Turrado 1966, 565), aparece 
también como consecuencia del desprecio por lo material. Finalmente el objetivo de la meditación debería ser el "perfecto amador al que de semejante manera procura transformarse en el amor de su Dios, que, transformado en Él, se haga una misma cosa en espíritu con Dios, en tanto grado que ose decir con San Pablo: 'Fuera sea de mí gloriarme en otra cosa sino en la cruz de nuestro Señor Jesucristo?"' (Villanueva 1952, 519)2. La Imitatio Christi es, por lo tanto, una posibilidad de amor Dei. Al definir la contemplación, Tomás parece referirse a Platón cuando la llama "alegre y deleitable admiración de la limpidísima y esclarecida verdad" (Villanueva 1952, 523; cf. Turrado 1958, 573).

También se encuentran elementos platónicos en sus sermones, cuando, por ejemplo, describe a Dios como "sumo bien" (Villanueva 1952, 602). Parte de la frase de Agustín "Nos hiciste, Señor, para ti, y nuestro corazón está inquieto mientras no descanse en ti" (Turrado 1966, 47, 49) cuando compara el alma con una piedra cuyo peso la atrae siempre a la tierra, es decir, al centro: "Así el amor lleva el ánima a su centro, que es Dios. Pues imita, ánima mía, a la naturaleza" (Villanueva 1952, 603). Se ha demostrado que Tomás de Villanueva, que, según Quevedo, de niño da su ropa a los pobres, lo hace desde una actitud de completa ruptura con el mundo material. En lugar de negocios y curiosidades del mundo prefiere deleites interiores del espíritu, en lugar de conversaciones sobre temas mundanos prefiere la buena lección, la meditación y la oración. Su objetivo es ser parte en lo sustancialmente bueno, la cosa cierta y esclarecida verdad, a través de la imitación de Cristo.

Dado que, obviamente, la categoría de imitación de modelos es de importancia en el platonismo cristianizado, se insertará un pequeño extracto a continuación. Con la imitatio sanctorum Isidoro de Sevilla no quiere detenerse en la veneración de los santos, sino que recomienda imitar sus actitudes y hechos. Algunos santos individuales representan virtudes especiales: Pablo por la piedad, Juan por el amor, Abraham por la obediencia, Isaac por la paciencia, Moisés por la dulzura y Josué por la constancia (Schiewer 2018, 186) ${ }^{3}$. La Legenda aurea del dominico Jacobo de Vorágine (1228/9-1298), que también apareció en forma impresa en 1470, presenta las vidas de los santos con la intención de conversión y mejoramiento. En tanto los asigna a temas teológicos, esta obra también podría servir para la preparación de sermones (Schiewer 2018, 165).

Aristóteles vio en la imitación, es decir, en la representación de la gente que actúa, la característica esencial de la poesía. En nuestro contexto, sin embargo,

2 Aquí se manifiesta un ejemplo divino de la caridad que hay que imitar (Cfr. Jobit 1961, 214).

3 Para la imitación de los santos cfr.: (Aragüés Aldaz 2007, 275-302)y (Redondo 2007, 303-26). 
la imitación se considera un principio esencial en los principios de la época moderna, independiente de la poesía. Nuestro tema es, pues, la imitatio morum, la imitación de figuras y modelos de vida ejemplares, no la poética imitatio rerum, que representa la realidad en el sentido aristotélico, o la imitatio auctorum, que imita a autores ejemplares, especialmente los de la antigüedad. ¿Quién fue imitado? Además de la imitatio Christi hay ideales bíblicos, figuras como David y Salomón como modelos para los reyes o Héctor y Aquiles como figuras modelo para los caballeros nobles. Un imitador como Francisco de Asís se transformó, como el otro Cristo (segundo Cristo), él mismo de imitador en imitado. En este caso, pero también en general, se plantea la interrogante de hasta qué punto una imitación refuerza o debilita la identidad del propio ser. La respuesta a esta pregunta depende, entre otras cosas, de cuánto se desea la imitación.

Sin embargo, independientemente de ello, es evidente que la doctrina de la imitación es comparable con la de la participación del individuo en la idea. Si el individuo siempre ha sido una imitación de la idea, entonces el bien en el mundo es la imitación de la idea del bien. Este bien puede ser imitado por la buena acción moral de personas individuales, que a su vez pueden ser imitadas para participar de la idea del bien a través de la parousía y la methexis. Es irrelevante si la idea suprema en sí misma o sus imitadores, como los santos o Cristo, son imitados. La consecuencia de la imitación es siempre la participación. Pero mientras que la cosa individual siempre ha sido una imitación de la idea, la imitación de Cristo o de los santos tiene un momento activo, por lo que autores como Tomás y Fray Luis exhortan a ello. En el caso de San Agustín, esta imitación lleva a la participación de la civitas Dei.

¿Qué papel juega la tradición del platonismo para Fray Luis de León? Conocía las enseñanzas platónicas de Marcilio Ficino y de la Academia de Florencia y cita al monje agustino y neoplatonista Agustín Steuco. En Salamanca es influenciado por el clima de la "escuela platónica" de los monjes agustinos españoles Dionisio Vázquez, Alonso de Orozco, Pedro Malón de Chaide y Cristóbal de Fonseca (Álvarez Turienzo 1996, 50-52). Según Argimiro Turrado, la escuela espiritual agustiniana de Salamanca se caracteriza por un neoplatonismo cristiano (Turrado 1966, 178).

En la introducción de su libro De los nombres de Cristo Luis de León expresa primero su desacuerdo con la prohibición de la Iglesia de difundir la Biblia en las lenguas vernáculas, ya que los textos originales fueron escritos en las lenguas vernáculas de la época. Después de todo, es mejor leer la Biblia que leer libros malos, como enfatiza, refiriéndose a Pablo: "Porque si, como alega san Pablo, las malas conversaciones corrompen las buenas costumbres, el libro torpe 
y dañado, que conversa con el que lee a todas horas y a todos los tiempos, ¿qué no hará?" (León 2008, 7). Contrapone a estos libros malos la conversación de tres amigos sobre los nombres dados a Jesús en la Biblia. Estos nombres son para él "como unas cifras breves, en que Dios maravillosamente encerró todo lo que acerca desto el humano entendimiento puede entender y le conviene que entienda" (León 2008, 12). Define el nombre como una palabra corta que sustituye aquello a lo que se refiere: "no en el ser real y verdadero que ello tiene, sino en el ser que le da nuestra boca y entendimiento" (León 2008, 20). Antes de que Fray Luis distinga entre los nombres comunes, los términos generales que se refieren a muchos objetos, y los nombres propios, que son propios de solo uno, analiza los diferentes significados de los "nombres". Al hacerlo, subclasifica el nombre como el signo en el sentido de Saussure en significante (signifiant) y significado (signifié), por lo que denomina a la arbitrariedad del significante "por arte" y al carácter no arbitrario del significado "por naturaleza" (León 2008, 23). "Los primeros son, el ser que tienen las cosas en el entendimiento del que las entiende; y los otros, el ser que tienen en la boca del que como las entiende las declara y saca a luz con palabras" (León 2008, 23). El primero, que Fray Luis también llama imagen o figura, lo describe como si fueran ideas platónicas. Así le son asignadas cosas materiales "demás del ser real que tienen en sí, otro ser del todo semejante a este mismo, pero más delicado que él, y que nace en cierta manera dél, con el cual estuviesen y viviesen cada una dellas en los entendimientos de sus vecinos, y cada una en todas, y todas en cada una" (León 2008, 21-22). Fray Luis compara los muchos objetos individuales que dependen de una idea con los espejos colocados de forma diferente delante de un objeto, que representan este único objeto de diferentes maneras.

Fray Luis distingue entre términos generales y "otros que son propios de sólo uno, y éstos son aquellos de quien hablamos agora" (León 2008, 24), pero deja abierto si en su obra De los nombres de Cristo Cristo es nombre propio y sus nombres son términos generales o se convierten en nombres propios. Fray Luis se refiere al Génesis 2, 19 cuando argumenta que, en hebreo, el idioma original, Adán "inspirado por Dios" (León 2008, 25) dio nombres a las cosas del Jardín del Edén. Básicamente, en el idioma original del hebreo, las palabras como criaturas de Dios tienen una similitud con sus significados (significación), su sonido y con sus letras escritas (León 2008, 28). En su Exposición del libro de Job, Fray Luis da ejemplos de la similitud de los nombres propios con sus poseedores. Cuando analiza los nombres de las hijas de Job, descubre en ellos palabras que sugieren características de sus poseedoras: "Y en lo primero se nos ofrecen algunas razones, unas llanas y que pertenecen a la historia, y otras de significación y sentido más secreto" (León 1950, 490). Aquí y en Los nombres 
de Cristo, las influencias cabalísticas son evidentes (Swietlicki 1996, 315). Sin embargo, Luis toma la explicación de nombres como pastor, camino o montaña, que se atribuyen a Cristo encarnado "conforme a los ricos tesoros de bien que encierra en sí su naturaleza humana, y conforme a las obras que en ella y por ella Dios ha obrado" (León 2008, 35).

En el idioma original, los nombres propios llevan secretos en sí mismos, y por lo tanto están fundamentados de cierta manera. Como ejemplo del hecho de que, hasta cierto punto, esto se ha conservado en el actual idioma español en términos generales, Fray Luis cita la palabra "corregidores" siendo éstos responsables de mantener la justicia en una ciudad, estando incluida la palabra "corregir", "porque el corregir lo malo es su oficio dellos" (León 2008, 24).

Sin embargo, se hace más difícil cuando se trata de las letras escritas de la palabra hebrea Dios, que se considera inefable. La palabra para él es "como imagen de la sencillez que hay en Dios por una parte, y de la infinita muchedumbre de perfecciones que por otra tiene, porque todo es una gran perfección, y aquella una es todas sus perfecciones" (León 2008, 30). Es que la perfecta sabiduría, la justicia y la misericordia están unificadas en ella. El hombre, sin embargo, tiene una participación en la verdad divina, aun cuando no pueda reconocerla: "Está presente junto con nuestro ser, pero muy lejos de nuestra vista y del conocimiento claro que nuestro entendimiento apetece" (León 2008, 32). Sin embargo, como emanación de la idea suprema, el hombre no puede reconocerla porque su cuerpo, en la tradición platónica, cautiva la mente. Fray Luis describe el camino de la vida como peregrinación "cuando volare desta cárcel de tierra en que metida en tinieblas, y saliere a lo claro y a lo puro de aquella luz" (León 2008, 34). No sólo se aplica aquí el Soma sema, sino que también se utilizan las metáforas del relato de la caverna platónica.

Como emanación, el hombre debe ser comparado con aquel del que emanó. "Consiste, pues, la perfección de las cosas en que cada uno de nosotros sea un mundo perfecto, para que por esta manera, estando todos en mí y yo en todos los otros, y teniendo el ser mío, se abrace y eslabone toda aquesta máquina del universo, y se reduzga a unidad la muchedumbre de sus diferencias [...] Lo cual es avecinarse la criatura a Dios, de quien mana, que en tres personas es una esencia, y en infinito número de excelencias no comprehensibles, una sola, perfecta y sencilla excelencia" (León 2008, 21). Para Fray Luis, el hombre como microcosmos es, por lo tanto, un reflejo del macrocosmos y, por lo tanto, como unidad contiene la pluralidad de la misma manera que, en el sentido de la idea platónica suprema, Dios como Creador es la unidad de la pluralidad de las criaturas. 
El sol, que encarna la idea suprema de la parábola platónica de la cueva, parece ser evocado por Fray Luis cuando compara el conocimiento más elevado con el sol: "¡Luce pues, o solo verdadero Sol! En mi alma, y luce con tan grande abundancia de luz, que con el rayo della juntamente mi voluntad encendida te ame, mi entendimiento esclarecido te vea" (León 2008, 20). La sabiduría así adquirida también recuerda a la de la idea suprema de Platón: "Y la propia y verdadera sabiduría del hombre es saber mucho de Cristo, y a la verdad es la más alta y más divina sabiduría de todas; porque entenderle a él es entender todos los tesoros de la sabiduría de Dios, que, como dice san Pablo, están en él encerrados" (León 2008, 11). La variedad de las virtudes se convierte en unidad en la idea absoluta, de modo que la justicia, la sabiduría y el poder se unen: "de la infinita muchedumbre de perfecciones [...] todo es uno" (León 2008, 30). Y cuando el individuo es parte de esta idea y esta idea se refleja en él, las ideas platónicas de la methexis y la parousía se manifiestan: "Dios está presente en nosotros, y tan vecino y tan dentro de nuestro ser como él mismo de sí; porque en él y por él, no solo nos movemos y respiramos, sino también vivimos y tenemos ser" (León 2008, 32).

El camino del filósofo platónico desde la cueva hasta el sol se convierte en una peregrinatio cristiana para Luis, cuyo camino describe. "Camino es nombre de Cristo. [...] lo que nos quiso enseñar a nosotros llamándose a sí camino nuestro" (León 2008, 69). También aquí se trata de una cuestión de ejemplo, imitación y participación. "Camino se llama en otra manera la profesion de vivir que escoge cada uno para sí mismo, su intento, y aquello que pretende o en la vida ó en algun negocio particular, y lo que se pone como por blanco" (León 2008, 70). La participación se produce a través de la imitación: "Cristo es el camino del cielo, porque si no es poniendo las pisadas en él y siguiendo su huella, ninguno va al cielo. Y no solo digo que habemos de poner los piés donde él puso los suyos, y que nuestras obras, que son nuestros pasos, han de seguir á las obras que él hizo”. El camino es al mismo tiempo ley moral y mandamiento: “Cómo no será Cristo camino, si se llama camino todo lo que es ley, regla y mandamiento que ordena y endereza la vida, pues es él solo la ley? Porque no solamente dice lo que habemos de obrar, mas obra lo que nos dice que obremos" (León 2008, 80).

Se ha demostrado que Fray Luis de León y Tomás de Villanueva recomiendan la lectura de libros religiosos. Su propio libro religioso de los nombres de Cristo da a Fray Luis la oportunidad de distinguir entre palabras escritas o habladas, objetos materiales, conceptos e ideas. Al hacerlo, asume la jerarquía de la alegoría platónica de la cueva. Sin embargo, cuando diferencia entre términos generales y nombres propios, ve en los nombres propios una motivación que 
descifra misteriosamente el carácter del portador del nombre propio. Esto es aún más cierto en el caso de los Nombres de Cristo que él comenta. Como la unidad de la pluralidad, el hombre, a través de la emanación, es parte de la unidad de la pluralidad del Creador, que Fray Luis denomina como infinita muchedumbre de perfecciones. Si Cristo tiene el nombre de camino, entonces es al mismo tiempo una norma moral, que no significa otra cosa que la exhortación a la imitatio Christi, que es de importancia fundamental tanto para Fray Luis como para Tomás de Villanueva. Cuando Fray Luis escribe: "en él y por él, no solo nos movemos y respiramos, sino también vivimos y tenemos ser" (León 2008, 32), se trata de una reformulación de la idea platónica de la methexis y la parousía. El hecho de que, tanto con Fray Luis como con Tomás de Villanueva, el mundo exterior se desvaloriza y el interior se revaloriza, el cuerpo se considera una prisión y el camino de la vida se describe metafóricamente como la peregrinatio de la oscuridad hacia la luz, distingue a ambos monjes agustinos como guardianes, trasmisores y cristianizadores de las enseñanzas platónicas.

\section{REFERENCIAS BIBLIOGRÁFICAS}

Aquino, Tomás de. Comentario a la Ética a Nicómaco de Aristóteles. Traducido por Ana Malla. Pamplona: EUNSA, 2000.

Álvarez Turienzo, Saturnino. "Fray Luis de León en el laberinto renacentista de idearios". En Fray Luis de León. Historia, humanismo y letras, editado por Víctor García de la Concha y Javier San José Lera, 43-62. Salamanca: Ediciones Universidad,1996.

Aragüés Aldaz, José. "Fronteras de la imitación hagiográfica". En Modelos de vida en la España del Siglo de Oro, editado porIgnacio Arellano y Marc Vitse et al., 275-302.Madrid: Iberoamericana, 2004, vol. 2.

Calatayud Gil, Carlos. "Santo Tomás de Villanueva y la Literatura". En Santo Tomás de Villanueva, Cinco conferencias, editado por J.M. Martínez Val et al., 23-29. Ciudad Real: Publicaciones del Instituto de Estudios Manchegos, 1956.

Gronau, Karl. Platons Ideenlehre im Wandel der Zeit.Braunschweig: Westermann, 1929.

Jobit, Pierre. L'évèque des pauvres. Saint Thomas de Villeneuve. Paris: Fayard, 1961.

León, Fray Luis de. Obras. Madrid: Ediciones Atlas, 1950.

León, Fray Luis de. De los nombres de Cristo, editado por Javier San José Lera. Barcelona: Círculo de Lectores, 2008.

Quevedo, Francisco de. "De la milagrosa vida del bienaventurado Fray Tomas de Villanueva, de la orden San Agustín, arzobispo de Valencia." En Obras, editado por Aureliano Fernández-Guerra. Madrid: Rivadeneyra, 1859, vol. 2. 
Redkova, Irina. "Die civitas Dei, ihre Wahrenhmung und Imitation in der Exegese des 12. Jahrhunderts". En Nachahmen im Mittelalter, editado por Andreas Büttner y al., 153-164. Köln: Böhlau, 2018.

Redondo, Agustín. "Un nuevo modelo de santidad en la España contrarreformista: el caso del jesuita Francisco Javier". En Modelos de vida en la España del Siglo de Oro, editado por Ignacio Arellano, Marc Vitse y al., 303-326. Madrid: Iberoamericana, 2004, vol. 2.

Schiewer, Regina D. "Heilige als role models für geistliche Frauen des 14. und 15. Jahrhunderts". En Nachahmen im Mittelalter, editado por Andreas Büttner y al., 165-188. Köln: Böhlau, 2018.

Swietlicki, Connor. "Fray Luis de León: El humanista más humano." En Fray Luis de León. Historia, humanismo y letras, editado por Víctor García de la Concha y Javier San José Lera, 313-322. Salamanca: Ediciones Universidad, 1996.

Turrado, Argimiro. "La teología de la caridad en Santo Tomás de Villanueva, maestro en espiritualidad agustiniana". La Ciudad de Dios 171 (1958): 564598.

Turrado, Argimiro. Espiritualidad agustiniano y vida de perfección. El ideal monástico agustiniano en Santo Tomas de Villanueva. Madrid: Ediciones religión y cultura, 1966.

Villanueva, Tomás de. "Modo breve de servir a nuestro señor en diez reglas." En Obras, editado por Santos Santamaría, 508-513. Madrid: BAC, 1952.

Villanueva, Tomás de. Obras, editado por Santos Santamaría. Madrid: BAC, 1952.

Christoph Strosetzki

Romanisches Seminar

Universität Münster

Bispinghof $3^{\text {a }}$, D 48143 Münster (Alemania) https://orcid.org/0000-0003-1288-9014 
